\title{
GMR
}

\section{Molecular mapping and candidate gene analysis for resistance to powdery mildew in Cucumis sativus stem}

\author{
P.N. Liu ${ }^{1 *}$, H. Miao ${ }^{1 *}$, H.W. Lu ${ }^{1}$, J.Y. Cui ${ }^{1}$, G.L. Tian${ }^{1}$, T.C. Wehner ${ }^{2}$, \\ X.F. Gu${ }^{1}$ and S.P. Zhang ${ }^{1}$ \\ ${ }^{1}$ Institute of Vegetables and Flowers, \\ Chinese Academy of Agricultural Sciences, Beijing, China \\ ${ }^{2}$ Department of Horticultural Science, \\ North Carolina State University, Raleigh, NC, USA \\ *These authors contributed equally to this study. \\ Corresponding authors: X.F. Gu / S.P. Zhang \\ E-mail: guxingfang@caas.cn / zhangshengping@caas.cn \\ Genet. Mol. Res. 16 (3): gmr16039680 \\ Received March 22, 2017 \\ Accepted July 21, 2017 \\ Published August 31, 2017 \\ DOI http://dx.doi.org/10.4238/gmr16039680
}

Copyright $(2017$ The Authors. This is an open-access article distributed under the terms of the Creative Commons Attribution ShareAlike (CC BY-SA) 4.0 License.

\begin{abstract}
Powdery mildew (PM) of cucumber (Cucumis sativus), caused by Podosphaera xanthii, is a major foliar disease worldwide and resistance is one of the main objectives in cucumber breeding programs. The resistance to PM in cucumber stem is important to the resistance for the whole plant. In this study, genetic analysis and gene mapping were implemented with cucumber inbred lines NCG-122 (with resistance to PM in the stem) and NCG-121 (with susceptibility in the stem). Genetic analysis showed that resistance to PM in the stem of NCG-122 was qualitative and controlled by a single-recessive nuclear gene $(\mathrm{pm}-\mathrm{s})$. Susceptibility was dominant to resistance. In the initial genetic mapping of the pm-s gene, $10 \mathrm{SSR}$ markers were discovered to be linked to $p m-s$, which was mapped to chromosome 5 (Chr.5) of cucumber. The pm-s gene's closest flanking markers were SSR20486 and SSR06184/ SSR13237 with genetic distances of 0.9 and $1.8 \mathrm{cM}$, respectively. One
\end{abstract}

Genetics and Molecular Research 16 (3): gmr16039680 
hundred and fifty-seven pairs of new SSR primers were exploited by the sequence information in the initial mapping region of $p m-s$. The analysis on the $\mathrm{F}_{2}$ mapping population using the new molecular markers showed that 17 SSR markers were confirmed to be linked to the $p m-s$ gene. The two closest flanking markers, pmSSR27and pmSSR17, were 0.1 and $0.7 \mathrm{cM}$ from $p m-s$, respectively, confirming the location of this gene on Chr.5. The physical length of the genomic region containing $p m-s$ was $135.7 \mathrm{~kb}$ harboring 21 predicted genes. Among these genes, the gene Csa5G623470 annotated as encoding Mlo-related protein was defined as the most probable candidate gene for the $p m-s$. The results of this study will provide a basis for marker-assisted selection, and make the benefit for the cloning of the resistance gene.

Key words: Cucumis sativus L.; Podosphaera xanthii; SSR marker; gene prediction

\section{INTRODUCTION}

Powdery mildew (PM) of cucumber (Cucumis sativus L.), caused by Podosphaera xanthii, is a major foliar disease worldwide (Barnes and Epps, 1956; Thomas, 1986). PM, downy mildew, and Fusarium wilt are the most significant diseases of cucumber in China (Cao et al., 2007). Powdery mildew occurs with small spots appearing on the foliage, and then foliage and stems were covered with a white, powdery mass of spores and hyphae successively (de Ruiter et al., 2008). The symptoms of PM are characterized by a short latent period, high secondary infection frequency, strong epidemic ability, and year-round presence. Besides, it develops and spreads rapidly in the middle and later phases of the growth period, and results in significant reductions in yields (Zhang et al., 2011). The most efficient method for controlling $\mathrm{PM}$ in cucumber is the use of resistant cultivars, and thus understanding the molecular biology of PM resistance plays a key role in cucumber breeding programs.

Reports about the inheritance of PM resistance genes in cucumber are various. Some reports state that resistance is a quantitative trait controlled by multiple recessive genes (Smith, 1948; Barnes and Epps, 1956; Fugieda and Akiya, 1962; Kooistra, 1968; Kooistm, 1971; Zhang et al., 2005; Sakata et al., 2006). However, Shanmugasundarum et al. (1971) differentiated between hypocotyl and leaf resistance and concluded that a recessive gene for hypocotyl resistance $(p m-h)$ is essential for overall resistance. He et al. (2013) and Walters et al. (2001) also showed that a single-recessive gene $(\mathrm{pm}-h)$ controls hypocotyl resistance, and the role of a single gene in resistance is supported by other studies (Zhang et al., 2004; Liu et al., 2008a). By contrast, some studies reported that resistance is controlled by a pair of incomplete recessive genes and two pairs of epistatic genes (Shanmugasundarum et al., 1971; Mao et al., 2005). Moreover, Morishita et al. (2003) suggested that resistance to PM is controlled by a pair of recessive genes and a pair of incompletely dominant genes and that resistance is temperature-dependent. There is no report of inheritance for the PM resistance in cucumber stem at the adult stage. The goal of this research was to determine the inheritance of resistance in the stem of inbred line NCG122.

The method used to determine resistance to PM in regular cucumber breeding programs requires evaluations in multiple locations, with replication to control environmental

Genetics and Molecular Research 16 (3): gmr16039680 
variation, including exposure to different regions of the pathogen, and to make valid selections for resistance over a period of several years of crossing and inbreeding. In contrast to disease ratings, it may be probable to select for resistance more efficiently using molecular markerassisted selection (MAS) (Zhang et al., 2013a). In cucumber, there are various studies about the molecular biology of PM resistance. Sakata et al. (2006) detected three quantitative trait loci (QTL) for PM resistance at $20^{\circ} \mathrm{C}$ and two at $26^{\circ} \mathrm{C}$. Of these, one major QTL was found to confer resistance at both $20^{\circ}$ and $26^{\circ} \mathrm{C}$. Liu et al. (2008b) identified five QTLs for PM resistance in three linkage groups in two environments. Zhang et al. (2011) reported four QTLs (pm5.1, pm5.2, pm5.3, and pm6.1) associated with PM resistance and pm5.2 on chromosome 5 (Chr.5) was a major QTL. Hofstede et al. (2008) and de Ruiter et al. (2008) identified two linked PM resistance QTLs, $p m-l$ and $p m-h$, conferring leaf resistance and hypocotyl resistance, respectively. He et al. (2013) defined six genomic regions in four chromosomes that harbored QTLs for PM resistance, and among them was QTL pm5.2 for hypocotyl resistance. Zhang (2006) and Zhang et al. $(2004,2007)$ reported AFLP markers linked to both resistant and susceptible genes for PM in cucumber, at genetic distances of 5.6 and $7.0 \mathrm{cM}$, respectively. Zhang et al. (2008) and He et al. (2013) reported SSR markers linked to resistant genes for powdery mildew in cucumber, at genetic distances of 2.6 and $13.0 \mathrm{cM}$. However, there are no reports on chromosomal mapping for PM resistance in the cucumber stem ( $\mathrm{pm}-\mathrm{s}$, a singlerecessive nuclear gene), and no reports on any molecular markers tightly linked to $\mathrm{pm}-\mathrm{s}$.

In the present study, inbred lines NCG-122 and NCG-121, with resistance and susceptibility to PM in cucumber stem, respectively, were applied to construct a genetic population for analyzing inheritance and mapping the $p m-s$ gene. The results will lay the foundation for future fine-mapping, gene cloning, and MAS breeding.

\section{MATERIAL AND METHODS}

\section{Experimental materials}

European greenhouse-type cucumber inbred lines NCG-122 $\left(\mathrm{P}_{1}\right.$, Figure 1A, resistant to PM in the stem) and NCG-121 ( $\mathrm{P}_{2}$, Figure 1B, susceptible to PM in the stem) were used as the parents for the $\mathrm{F}_{1}$, reciprocal $\mathrm{F}_{1}\left(\mathrm{~F}_{1}{ }^{\prime}\right)$, and $\mathrm{F}_{2}$ populations. The two inbreds were preserved by T.C. Wehner at North Carolina State University, USA.

\section{Experiment design}

All plants were grown under a clear plastic tunnel at Institute of Vegetables and Flowers, Chinese Academy of Agricultural Sciences, during 2013 and 2014. Ten plants each of $\mathrm{P}_{1}, \mathrm{P}_{2}, \mathrm{~F}_{1}, \mathrm{~F}_{1}$ ' were planted in the spring of 2014 in a randomized complete block with three replications. A total of 181 plants of $\mathrm{F}_{2}$ were also planted. The distances between plants and lines were 25 and $55 \mathrm{~cm}$, respectively.

\section{Disease investigation and data statistics}

The symptoms of PM disease occurred naturally in the disease nursery and were evaluated at the later stage of life (10-12 weeks after planting), as either resistant (no PM symptoms at all on the stem) or susceptible (sporulating PM colonies visible on the stem).

Genetics and Molecular Research 16 (3): gmr16039680 
Each plant was assessed by two investigators. The segregation ratio was analyzed using the SAS 9.2 and Microsoft Excel 2003 software.

\section{Construction of SSR linkage groups and initial chromosomal mapping of the pm-s gene}

SSR primers (2112) from cucumber genetic map by Ren et al. (2009) were used to map the $p m$-s gene initially. The modified CTAB method was used for the isolation of genomic DNA from young leaf tissue from each of the 30 plants used for $\mathrm{P}_{1}, \mathrm{P}_{2}, \mathrm{~F}_{1}, \mathrm{~F}_{1}$, and for each plant of the $\mathrm{F}_{2}$ population. The SSR reaction system was the same as that used by Zhang et al. (2014). Join Map 4.0 (Van Ooijen, 2006) was used to construct a linkage map.

The linkage map was constructed by screening SSR markers that showed polymorphisms between paternal and maternal parents and then using BSA method (Michelmore et al., 1991) to obtain DNA from either seven resistant or seven susceptible plants in the $\mathrm{F}_{2}$ generation to form the gene pool for primer screening. Finally, primers that had been screened for polymorphisms were used to analyze the genotypes of each plant in the $\mathrm{F}_{2}$ population, and construct the linkage map using Join Map 4.0.

The linkage map obtained in this study was compared with a previous integration map (Zhang et al., 2012), and the linkage groups and chromosomal location of the $\mathrm{pm}-\mathrm{s}$ gene identified.

\section{Development of new molecular markers and second mapping of the $p m-s$ gene}

In the initial mapping region harboring the $p m-s$ gene, new SSR primers were designed based on the full-sequence information of the cucumber genome (Huang et al., 2009). The new primers and 10 pairs of SSR primers published by He et al. (2013) were first used to screen for polymorphisms in the parents. Then, selected primers were used in the $F_{2}$ population to determine whether or not they were linked to the $p m-s$ gene.

\section{Sequence annotation and gene prediction in the genomic region containing the pm-s gene}

The sequences were aligned with the cucumber genome sequences (Huang et al., 2009) using BLASTn with an E-value cutoff of $1 \times 10^{-20}$. Only matches with an identity of more than $95 \%$ were retained. Gene prediction and annotation was accomplished just as Zhang et al. (2013b).

\section{RESULTS}

\section{Inheritance of the resistance to PM in the NCG122 cucumber stem}

The parental lines $\mathrm{P}_{1}$ (NCG-122) and $\mathrm{P}_{2}$ (NCG-121) were resistant and susceptible, respectively (Figure 1A and B), and the $\mathrm{F}_{1}$ and reciprocal $\mathrm{F}_{1}$ of NCG-122 $\mathrm{x}$ NCG-121 were all susceptible. In the $\mathrm{F}_{2}$ population, there were 133 plants susceptible and 48 plants resistant. The chi-square analysis $\left(\chi^{2}=0.27<3.841\right)$ showed a segregation ratio of $3: 1$ (Table 1$)$. In the backcross population of $\mathrm{BC}_{1} \mathrm{P}_{1}$, there were 43 plants resistant and 45 plants susceptible. The chi-square analysis $\left(\chi^{2}=0.05<3.841\right)$ showed a segregation ratio of $1: 1$ (Table 1$)$. In the backcross population of $\mathrm{BC}_{1} \mathrm{P}_{2}$, all the plants (87 plants) were susceptible. Therefore, the resistance to PM in the NCG-122 stem was consistent with the control by the pm-s gene. The susceptibility was dominant over the resistance.

Genetics and Molecular Research 16 (3): gmr16039680 


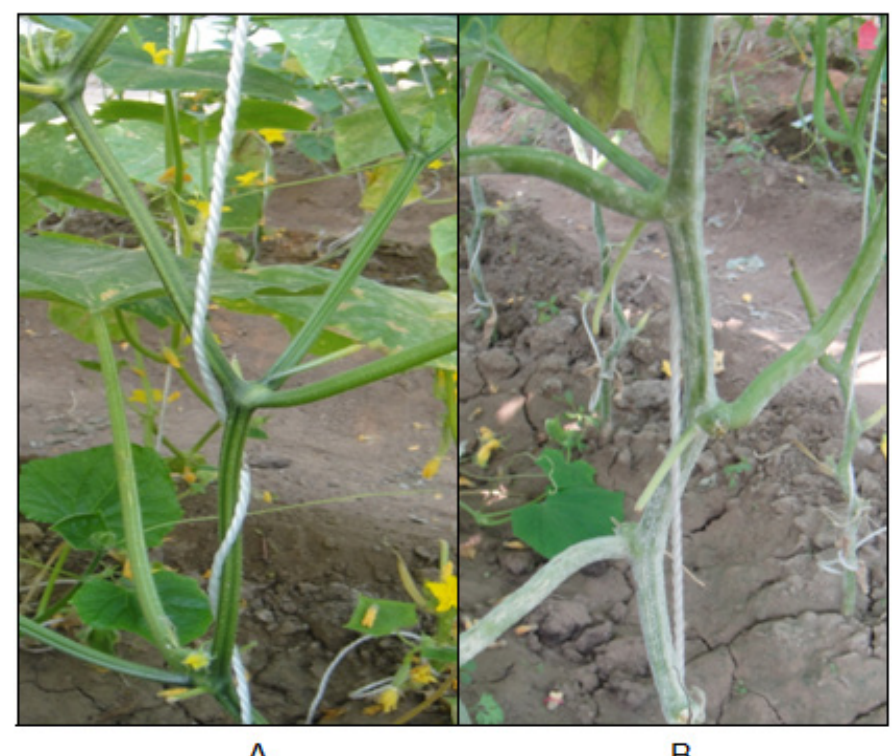

A

B

Figure 1. Phenotype pictures of the parental lines. A. $\mathrm{P}_{1}$ (NCG-122 with high resistance to powdery mildew in cucumber stem). B. $\mathrm{P}_{2}$ (NCG-121 with high susceptibility to powdery mildew in cucumber stem).

Table 1. Segregation ratios of disease-resistant and disease-susceptible plants in NCG122 x NCG121 genetic populations.

\begin{tabular}{l|c|c|c|c|c}
\hline Populations & No. of total plants & No. of disease-resistant plants (R) & No. of disease-susceptible plants (S) & Expected ratio (R:S) & Goodness of fit $\chi^{2}$ \\
\hline $\mathrm{P}_{1}($ NCG122) & 10 & 10 & 0 & - & \\
\hline $\mathrm{P}_{2}$ (NCG121) & 10 & 0 & 10 & - & \\
\hline $\mathrm{F}_{1}$ & 10 & 0 & 10 & - & \\
\hline $\mathrm{BC}_{1} \mathrm{P}_{1}$ & 88 & 43 & 45 & $1: 1$ & \\
\hline $\mathrm{BC}_{1} \mathrm{P}_{2}$ & 87 & 0 & 87 & - & 0.05 \\
\hline $\mathrm{F}_{2}$ & 181 & 48 & 133 & $1: 3$ & 0.27 \\
\hline
\end{tabular}

\section{Construction of SSR linkage groups and initial chromosomal mapping of the pm-s gene}

Of the 2112 pairs of SSR primers tested, 282 (13.4\%) showed obvious polymorphisms between the parental lines NCG-122 and NCG-121. These primers were used to look for polymorphisms in the genomic DNA bulks prepared from the resistant and susceptible plants. Ten pairs $(3.5 \%)$ were chosen to analyze the DNA from 181 plants in the $\mathrm{F}_{2}$ population. The resulting data were used to construct a linkage group using Join Map 4.0 $(\mathrm{LOD}=10)$. The total length of the linkage group was $16.3 \mathrm{cM}$, and the average genetic distance was $1.6 \mathrm{cM}$. The $p m-s$ gene was located between SSR20486 and SSR06184/SSR13237 with genetic distances of 0.9 and $1.8 \mathrm{cM}$, respectively (Figure 2B).

\section{Second mapping of the pm-s gene using new molecular markers}

One hundred and forty-seven pairs of new SSR primers were designed by the genome sequence of the initial mapping region of the $p m-s$ gene. Four of these and three of 10 pairs of SSR primers published by He et al. (2013) showed polymorphisms among the parents and 
were used to analyze the $\mathrm{F}_{2}$ mapping population. Then, a new linkage group was constructed with $17 \mathrm{SSR}$ primers, and a total length of $20.4 \mathrm{cM}$ (see Table 2 for names and sequences of the primers). Among these, the markers most closely linked to the $p m-s$ gene were pmSSR 27 and pmSSR17, with genetic distances of 0.1 and $0.7 \mathrm{cM}$, respectively (Figure 2C).

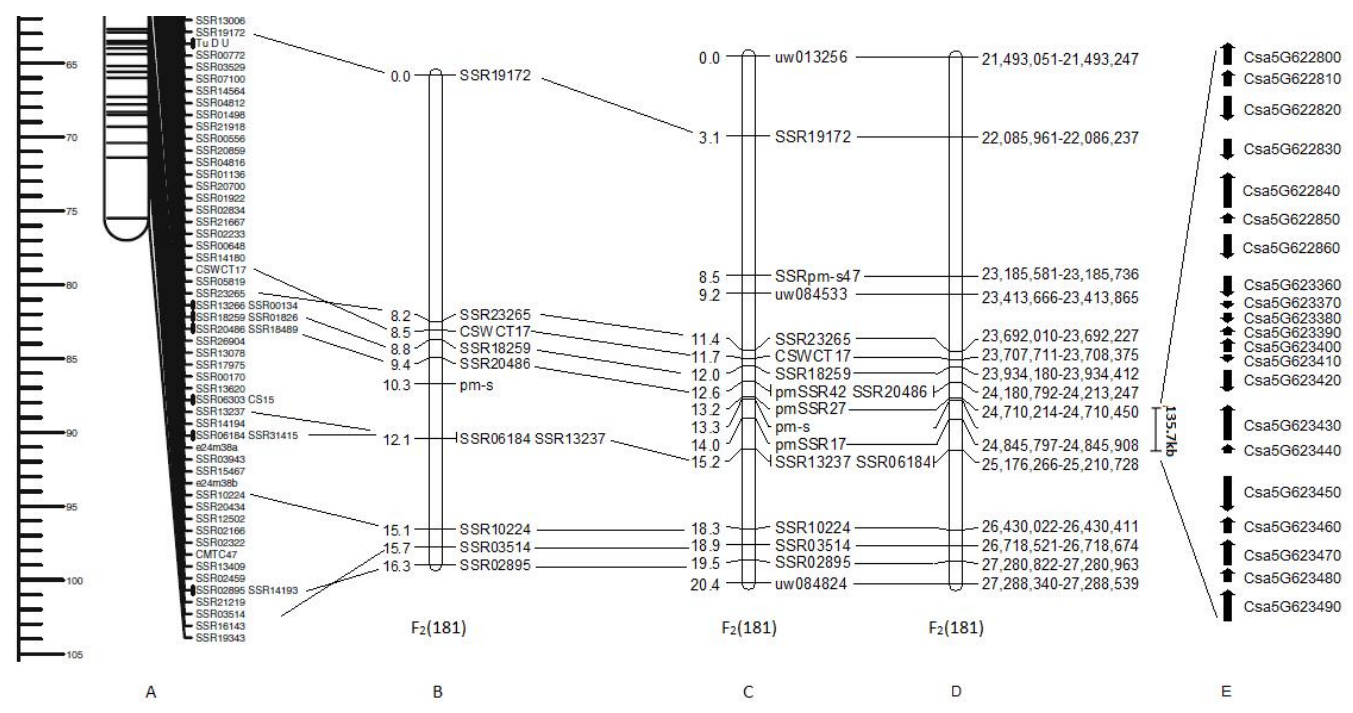

Figure 2. Molecular marker linkage and chromosomal mapping of the pm-s gene in cucumber. A. Chromosome 5 of cucumber. B. SSR linkage of the $p m-s$ gene for preliminary mapping. C. Linkage of molecular markers to the $p m-s$ gene for second mapping. D. Physical map of molecular markers. E. Predicted genes among the flanking markers.

Table 2. Sequence of SSR for the genetic linkage map of the $p m-s$ gene in cucumber.

\begin{tabular}{|c|c|c|c|c|}
\hline Primer name & Forward primer & Reverse primer & Motif & Fragment size \\
\hline UW013256 & CGACGTCTGTGTTTCTCTGG & GCCCCAAAAGGATGGATTAT & $(\mathrm{CT})_{3}$ & 197 \\
\hline SSR19172 & CGAGGAGAAGGACTACGACG & CGTGTGGAGCTTTCTCACAA & $(\mathrm{CAC})_{11}$ & 277 \\
\hline UW084533 & TTCCCTCTATCAACAATGTCCA & TTTCCTTCTAAAAATTGAACTATCAC & $(\mathrm{AG})_{10}$ & 200 \\
\hline SSRpm-s47 & CGGAAGTAGCATTGTTAGAGGA & GAAGCCTCCATTATCACCACAA & $(\mathrm{AG})_{3}$ & 156 \\
\hline SSR23265 & CCTCCСТCCATTTTCCACTA & TGAGCCAGTTGGGGTTTTAG & $(\mathrm{CT})_{19}$ & 218 \\
\hline CSWCT17 & TTGAATTATGGGTTCATTTTT & GACAATGATAAACTTCCCTGA & $(\mathrm{TG})_{11}$ & 180 \\
\hline SSR18259 & CGGTTTCTTCTGGCAAATGT & TTCCCTCAGCAGTCTCCAAT & $(\mathrm{TC})_{17}$ & 233 \\
\hline SSR20486 & ATAAACAGGGATCACGGCTG & CAGTTCAAGTGCAATCACCG & (CACTTC) 8 & 154 \\
\hline pmSSR42 & CAGCCACACTGACCTTTGGA & GCTCAGTGGGTTTGATCCTCT & $($ AATTCA) 4 & 224 \\
\hline pmSSR27 & CCCTATGCGTGAAAGCCACT & CGCCTCAAACCCATACCCAA & $(\mathrm{AAT})_{7}$ & 237 \\
\hline pmSSR17 & CGGAGACAGCTGTTGGTCAA & GAGTGAGGTAGAGGTGAGGGT & $(\text { TGGGTA })_{4}$ & 112 \\
\hline SSR13237 & AGGGAGTTGGAAGAGGTGGT & AGTGAAAACAGTCAGGAGGTGA & $(\mathrm{A})_{56}$ & 205 \\
\hline SSR06184 & ACTAACCAAACCAACGTCCG & CAGGCTTAATTGTTAAGAAAACAGAA & $\left(\right.$ TCATC $_{6}$ & 192 \\
\hline SSR10224 & AAGTGAGTTGCAATGGCTGA & TCCATTGAGGTGATCTGAAAAA & $(\mathrm{TC})_{19}$ & 390 \\
\hline SSR03514 & TAGGGTCCCCTTCCCTCATA & GGGTACCCAAAAGCAAGTGA & $(\mathrm{TC})_{14}$ & 154 \\
\hline SSR02895 & GAGTTGGCAAGTCACGTTGT & TTTCCCTCATTATGCCATCC & $(\mathrm{AT})_{19}$ & 142 \\
\hline UW084824 & AAGATCACTGCCTCAATCTCGTAT & CTCACGTGCCGAGATTAAGAA & $(\mathrm{AT})_{12}$ & 200 \\
\hline
\end{tabular}

Sequence annotation and gene prediction in the genomic region harboring the $\mathrm{pm}-\mathrm{s}$ gene

The physical distance between pmSSR27 and pmSSR17, the two flanking markers tightly linked to the $p m-s$ gene, was about $135.7 \mathrm{~kb}$ (Figure 2D). A total of 21 predicted candidate genes 
were located in the region, and their distribution on the chromosome is shown in Figure 2E. Fifteen of these predicted candidate genes have functional annotation, and these annotated genes include BTB/POZ fold, Ribophorin, zinc finger, peptidase family, NUDIX hydrolase conserved site, major intrinsic protein, alpha/beta hydrolase $\mathrm{N}$-terminal, transferase, acyl hydrolase, Mlo-related protein, Tetraspanin, and serine carboxypeptidase (Table 3). Csa5G623470 predicted to encode Mlo-related protein is the most likely candidate gene for the $\mathrm{pm}-\mathrm{s}$. The functional annotation of this gene showed organized defense response to fungus and participated in cell death.

\begin{tabular}{|c|c|c|}
\hline Candidate genes & Position & Function \\
\hline Csa5G622800 & $24,708,800-24,712,077$ & \\
\hline Csa5G622810 & $24,713,278-24,716,307$ & IPR000210 BTB/POZ-like; IPR004249 NPH3; IPR011333 BTB/POZ fold; IPR013069 BTB/POZ \\
\hline Csa5G622820 & $24,717,496-24,721,550$ & IPR007676 Ribophorin I \\
\hline Csa5G622830 & $24,735,193-24,738,505$ & IPR000679 Zinc finger GATA-type; IPR013088 Zinc finger NHR/GATA-type; IPR016679 Transcription factor GATA plant \\
\hline Csa5G622840 & $24,741,435-24,750,050$ & IPR007484 Peptidase M28 \\
\hline Csa5G622850 & $24,750,072-24,750,730$ & 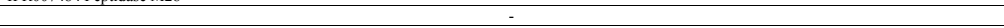 \\
\hline Csa5G622860 & $24,752,324-24,756,109$ & $\begin{array}{l}\text { IPR000086 NUDIX hydrolase domain; IPR007722 mRNA decapping protein } 2 \text { box A; IPR015797 NUDIX hydrolase domain-like; IPR020084 NUDIX } \\
\text { hydrolase conserved site }\end{array}$ \\
\hline Csa5G623360 & $24,762,529-24,766,481$ & IPR000425 Major intrinsic protein; IPR012269 Aquaporin; IPR022357 Major intrinsic protein conserved site; IPR023271 Aquaporin-like \\
\hline Csa5G623370 & $24,766,751-24,767,082$ & 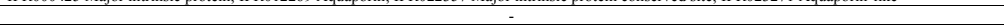 \\
\hline Csa5G623380 & $24,769,944-24,771,510$ & IPR022742 Alpha/beta hydrolase N-terminal \\
\hline Csa5G623390 & $24,773,390-24,773,916$ & (1) \\
\hline Csa5G623400 & $24,774,031-24,776,029$ & - \\
\hline Csa5G623410 & $24,777,415-24,777,798$ & \\
\hline Csa5G623420 & $24,781,456-24,785,158$ & IPR002641 Patatin/Phospholipase A2-related; IPR016035 Acyl transferase/acyl hydrolase/lysophospholipase \\
\hline Csa5G623430 & $24,790,747-24,798,753$ & $\begin{array}{l}\text { IPR000991 Glutamine amidotransferase class-I C-terminal; IRR001317 Carbamoyl-phosphate synthase GATase domain; IPR005801 ADC synthase; } \\
\text { IPR005802 Para-aminobenzoate synthase component I; IPR006220 Anthranilate synthase component II/delta crystallin; IPR006221 Anthranilate synthase } \\
\text { glutamine amidotransferase; IPR006805 Anthranilate synthase component I N-terminal; IPR011702 Glutamine amidotransferase superfamily; IPR015890 } \\
\text { Chorismate binding C-terminal; IPR017926 Glutamine amidotransferase type 1 }\end{array}$ \\
\hline Csa5G623440 & $24,798,793-24,799,324$ & \\
\hline Csa5G623450 & $24,815,415-24,823,422$ & IPR000719 Protein kinase catalytic domain; IPR002575 Aminoglycoside phosphotransferase; IPR004147 ABC-1; IPR011009 Protein kinase-like domain \\
\hline Csa5G623460 & $24,823,711-24,825,973$ & $\begin{array}{l}\text { IPR000608 Ubiquitin-conjugating enzyme E2; IPR015582 Ubiquitin-conjugating enzyme E2 H10; IPR016135 Ubiquitin-conjugating enzyme/RWD-like; } \\
\text { IPR023313 Ubiquitin-conjugating enzyme active site }\end{array}$ \\
\hline Csa5G623470 & $24,827,408-24,831,456$ & IPR004326 Mlo-related protein \\
\hline Csa5G623480 & $24,835,878-24,838,039$ & IPR018499 Tetraspanin \\
\hline Csa5G623490 & $24,840,363-24,845,726$ & IPR001563 Peptidase S10 serine carboxypeptidase; IPR018202 Peptidase S10 serine carboxypeptidase active site \\
\hline
\end{tabular}

\section{DISCUSSION}

Several reports about the inheritance of resistance to PM in cucumber are available, but the conclusions often disagree (Barnes and Epps, 1956; Fugieda and Akiya, 1962; Kooistm, 1971; Shanmugasundarum, 1971; Morishita et al., 2003). The reasons for this include factors such as 1) differences in pathogenicity and race differentiation within PM;2) differences in cultivars and breeding lines of cucumber; 3 ) differences in methods of disease evaluation methods and rating scales; 4) differences in the environmental conditions used during testing for PM resistance; 5) possible complexity in the inheritance of PM resistance; and 6) whether PM resistance is treated as a quantitative trait or targeted in different parts of the plant. This study focused on the inheritance of resistance to PM in the cucumber stem, thus eliminating the influence of other genes. It was determined that the $\mathrm{pm}-\mathrm{s}$ gene controls the resistance to PM in the NCG-122 cucumber stem, and that the $p m-s$ gene is located within a genetic distance of $0.8 \mathrm{cM}$ on Chr.5. The tightly linked SSR markers to the $p m-s$ resistance gene found in this research will be applied in marker-assisted selection to improve the quality and marketability of cucumbers.

An MLO-like gene (Csa5G623470) was identified in the genomic region harboring the $p m-s$ gene after sequence annotation and gene prediction. The gene belonged to $M L O$ homology protein family with seven transmembrane domains. In barley and Arabidopsis thaliana, the mlo gene was a kind of recessive gene with positive defense reaction to PM. The function incapacitation of the susceptible gene caused durable and broad-spectrum resistance to PM (Büschges et al., 1997; Consonni et al., 2006). In cucumber, the gene was identified as 
the resistance gene to PM in cucumber hypocotyl by Berg et al. (2015). In the same physical region harboring the $p m-s$, Nie et al. (2015) also found an MLO-like gene. So, Csa5G623470 was speculated as the resistance gene for powdery mildew in cucumber stem in the present study. To prove, this guess will be the next focus of our study. We will narrow down the physical distance of the $p m-s$ gene by fine-mapping technique, and clone the gene using mapbased cloning method.

So far, there are no reports of chromosomal mapping for PM resistance in cucumber stem $(p m-s)$, and no reports of any molecular markers tightly linked to $p m-s$. SSR markers (2112 pairs) were first applied to map the resistance to PM in cucumber stem in our study. The molecular markers defined in the present research will be good for MAS breeding. Moreover, the results of this study will lay the good foundation for cloning the resistance gene. An MLO-like gene, which is important to the resistance to PM in cucumber, identified on Chr.5 in our study was also reported by Nie et al. (2015). In this point, the results of the two studies could corroborate and support each other. The differences between the two types of research are as follows. Firstly, the plant materials were different. Cucumber inbred line S1003 was used as plant material in the study of Nie et al. (2015). S1003 belonged to East Asian type cucumber. The resistance to PM in S1003 was quantitative and conferred by multiple genes. The European greenhouse-type cucumber inbred line NCG122 was used in our study. The resistance to PM in the NCG122 stem was qualitative and conferred by the single recessive gene. Secondly, the disease rating methods were different. Nie et al. (2015) screened the whole seedling (including leaves) for disease rating, while we just focused on the stem (no leaves) for disease rating. Thirdly, the technique for molecular marker analysis was different. Windows QTL Cartographer 2.5 was used for QTL detecting in the previous study, while the bulked segregant analysis technology was adopted for gene mapping in the present study.

\section{CONCLUSION}

Genetic analysis revealed that resistance to PM in the stem of NCG-122 was qualitative and controlled by the $p m-s$ gene. The $p m-s$ gene was mapped between pmSSR27 and pmSSR 17, with genetic distances of 0.1 and $0.7 \mathrm{cM}$, respectively, confirming the location of this gene on Chr.5. The physical length of the genomic region harboring $p m-s$ was 135.7 $\mathrm{kb}$ containing 21 predicted genes. Among these genes, the gene Csa5G623470 annotated as encoding Mlo-related protein was identified as the most likely candidate gene for the $p m-s$.

\section{Conflicts of interest}

The authors declare no conflict of interest.

\section{ACKNOWLEDGMENTS}

The authors would like to thank Dr. Graham Collins, formerly of the University of Adelaide, South Australia, for proofreading. Research supported by the National Natural Science Foundation of China (Grant \#31272187); the Core Research Budget of the Non-Profit Governmental Research Institution (ICS, CAAS; \#2014JB02-004); the Earmarked Fund for Modern Agro-Industry Technology Research System (CARS-25); and the Key Laboratory of Biology and Genetic Improvement of Horticultural Crops, Ministry of Agriculture, China.

Genetics and Molecular Research 16 (3): gmr16039680 


\section{REFERENCES}

Barnes WC and Epps WM (1956). Powdery mildew resistance in South Carolina cucumbers. Plant Dis. Res. 40: 1093.

Berg JA, Appiano M, Santillán Martínez M, Hermans FWK, et al. (2015). A transposable element insertion in the susceptibility gene $C s a M L O 8$ results in hypocotyl resistance to powdery mildew in cucumber. BMC Plant Biol. 15: 243. https://doi.org/10.1186/s12870-015-0635-x

Büschges R, Hollricher K, Panstruga R, Simons G, et al. (1997). The barley Mlo gene: a novel control element of plant pathogen resistance. Cell 88: 695-705. https://doi.org/10.1016/S0092-8674(00)81912-1

Cao QH, Wan HJ and Chen JF (2007). Progress on downy mildew resistance in cucumber. China Cucurbits Veget 1: 27-30.

Consonni C, Humphry ME, Hartmann HA, Livaja M, et al. (2006). Conserved requirement for a plant host cell protein in powdery mildew pathogenesis. Nat. Genet. 38: 716-720. https://doi.org/10.1038/ng1806

de Ruiter W, Hofstede R, de Vries J and van den Heuvel H (2008). Combining QTL for resistance to CYSDV and powdery mildew in a single cucumber line. In: Proc. 9th EUCARPIA meeting on genetics and breeding of Cucurbitaceae (Pitrat M, ed.). INRA, Avignon, May 21-24: 181-188.

Fugieda K and Akiya Y (1962). Genetic study of powdery mildew resistance and spine color on fruit in cucumber. J. Jpn. Soc. Hortic. Sci. 31: 30-32. https://doi.org/10.2503/jishs.31.30

He X, Li Y, Pandey S, Yandell BS, et al. (2013). QTL mapping of powdery mildew resistance in WI 2757 cucumber (Cucumis sativus L.). Theor. Appl. Genet. 126: 2149-2161. https://doi.org/10.1007/s00122-013-2125-6

Hofstede R, de Ruiter W, de Vries RJ and van den Heuvel H (2008). Disease resistant cucumber plants. US Patent (\# US2008/0307540 A1).

Huang S, Li R, Zhang Z, Li L, et al. (2009). The genome of the cucumber, Cucumis sativus L. Nat. Genet. 41: 1275-1281. https://doi.org/10.1038/ng.475

Kooistra E (1968). Powdery mildew resistance in cucumber. Euphytica 17: 236-244.

Kooistm E (1971). Inheritance of flesh and skin colors in powdery mildew resistance cucumber (Cucummis sativas L). Euphytica 20: 521-523.

Liu LZ, He HL and Pan JS (2008a). Genetic test of resistance to powdery mildew for cucumber germplasm R17. Resour. Utiliz. 27: 46-48.

Liu LZ, Yuan XJ, Cai R, Pan JS, et al. (2008b). Quantitative trait loci for resistance to powdery mildew in cucumber under seedling spray inoculation and leaf disc infection. J. Phytopathol. 156: 691-697. https://doi.org/10.1111/j.1439$\underline{0434.2008 .01427 . \mathrm{x}}$

Mao AJ, Zhang F, Zhang HY, Zhang LR, et al. (2005). Inheritance of resistance to powdery mildew in two cucumber varieties. Zhongguo Nongxue Tongbao 21: 302-305.

Michelmore RW, Paran I and Kesseli RV (1991). Identification of markers linked to disease-resistance genes by bulked segregant analysis: a rapid method to detect markers in specific genomic regions by using segregating populations. Proc. Natl. Acad. Sci. USA 88: 9828-9832. https://doi.org/10.1073/pnas.88.21.9828

Morishita M, Sugiyam K, Saito T and Sakata Y (2003). Powdery mildew resistance in cucumber. Jpn. Agric. Res. Q. 37: 7-14. https://doi.org/10.6090/jarq.37.7

Nie JT, He HL, Peng JL, Yang XQ, et al. (2015). Identification and fine mapping of pm5.1: a recessive gene for powdery mildew resistance in cucumber (Cucumis sativus L.). Mol. Breed. 35: 7. https://doi.org/10.1007/s11032-015-0206-8

Ren Y, Zhang Z, Liu J, Staub JE, et al. (2009). An integrated genetic and cytogenetic map of the cucumber genome. PLoS One 4: e5795. https://doi.org/10.1371/journal.pone.0005795

Sakata Y, Kubo N, Morishita M, Kitadani E, et al. (2006). QTL analysis of powdery mildew resistance in cucumber (Cucumis sativus L.). Theor. Appl. Genet. 112: 243-250. https://doi.org/10.1007/s00122-005-0121-1

Shanmugasundarum S, Williams PH and Peterson CE (1971). Inheritance of resistance to powdery mildew in cucumber. Phytopathology 61: 1218-1221. https://doi.org/10.1094/Phyto-61-1218

Smith PG (1948). Powdery mildew resistance in cucumber. Phytopathology 39: 1027-1028.

Thomas CE (1986). Downy and powdery mildew resistant muskmelon breeding line MR-1. HortScience 21: 329-329.

Van Ooijen JW (2006). JoinMap ${ }^{\circledR}$ 4, Software for the calculation of genetic linkage maps in experimental populations. Kyazma BV Wageningen 33: 10-1371.

Walters SA, Shetty NV and Wehner TC (2001). Segregation and linkage of several genes in cucumber. J. Am. Soc. Hortic. Sci. 126: 442-450.

Zhang GH, Du SL, Wang M and Ma DH (2004). AFLP markers of cucumber powdery mildew resistance-related gene. Yuan Yi Xue Bao 31: 189-192.

Zhang HY (2006). Identification of molecular markers linked to important resistant genes and construction of genetic map in cucumber. Beijing: Chin. Acad. Agricult. Sci. (in Chinese).

Genetics and Molecular Research 16 (3): gmr16039680 
Zhang HY, Wang ZG, Mao AJ, Zhang F, et al. (2008). SSR markers linked to the resistance genes of cucumber powdery mildew. Huabei Nongxuebao 23: 77-80.

Zhang SP, Liu MM, Miao H, Zhang SQ, et al. (2011). QTL mapping of resistance genes to powdery mildew in cucumber (Cucumis sativus L.). Zhongguo Nong Ye Ke Xue 44: 3584-3593.

Zhang SP, Liu MM, Miao H, Zhang SQ, et al. (2013a). Chromosomal mapping and QTL analysis of resistance to Downy Mildew in Cucumis sativus. Plant Dis. 97: 245-251. https://doi.org/10.1094/PDIS-11-11-0941-RE

Zhang S, Miao H, Sun R, Wang X, et al. (2013b). Localization of a new gene for bitterness in cucumber. J. Hered. 104: 134-139. https://doi.org/10.1093/jhered/ess075

Zhang SP, Miao H, Yang YH, Xie BY, et al. (2014). A major QTL conferring resistance to fusarium wilt using recombinant inbred lines of cucumber. Mol. Breed. 34: 1805-1815. https://doi.org/10.1007/s11032-014-0140-1

Zhang SQ, Gu XF, Zhang SP and Zou ZR (2005). The genetic mechanism of resistance to powdery mildew in cucumber. Yuan Yi Xue Bao 32: 899-901.

Zhang SQ, Gu XF, Zhang SP and Zou ZR (2007). Inheritance of powdery mildew resistance in cucumber and development of an AFLP marker for the resistance detection. Agric. Sci. China 11: 1336-1342. https://doi.org/10.1016/S1671$\underline{2927(07) 60181-3}$

Zhang WW, Pan JS, He HL, Zhang C, et al. (2012). Construction of a high density integrated genetic map for cucumber (Cucumis sativus L.). Theor. Appl. Genet. 124: 249-259. https://doi.org/10.1007/s00122-011-1701-x

Genetics and Molecular Research 16 (3): gmr16039680 